\title{
Analyzing the quality and validity of holmium laser enucleation of prostate (HoLEP) videos on social media
}

\author{
Emrullah Sogutdelen ${ }^{1}$, Senol Tonyali ${ }^{2}$ \\ ${ }^{1}$ Department of Urology, Bolu Abant Izzet Baysal University, Bolu, Turkey \\ ${ }^{2}$ Department of Urology, Istanbul University Faculty of Medicine, Istanbul, Turkey
}

Videosurgery Miniinv 2022; 17 (1): 226-231

DOI: https://doi.org/10.5114/wiitm.2021.107758

\begin{abstract}
Introduction: The number of social media users is gradually increasing, and they are spending their time gathering a lot of useful information for themselves. Here, we analysed the quality of Holmium Laser Enucleation of Prostate (HoLEP) surgery videos on YouTube.

Aim: To assess the quality of the most viewed HoLEP videos on YouTube using validated questionnaires and scoring systems developed to evaluate the significant features.

Material and methods: The most viewed 98 videos were included in this study by the search for 'Holep' keyword on YouTube. The Journal of American Medical Association Benchmark Score (JAMAS) and Global Quality Score (GQS) were used to analyse the videos after the validated HoLEP Scoring System Score (HSSS) was performed by 3 HoLEP trained surgeons to evaluate the technical quality of videos.

Results: The videos including surgical technique (76.5\%) and uploaded by urologists $(63.3 \%)$ constituted the majority of videos. The median of JAMAS, GQS, and HSSS were 1 (0-3), $2(0-4)$, and $1.5(0-11)$, respectively. The mean GQS and JAMAS of videos uploaded by academic centres was higher than those uploaded by commercial centres and urologists ( $p=0.01 ; p=0.01$, respectively). The mean HSSS was lower in the videos uploaded in the last 5 years, while JAMAS was higher ( $p=0.03, p=0.005$, respectively). The mean GQS and HSSS of videos with higher likes were found statistically significantly higher $(p=0.01 ; p=0.02$, respectively).

Conclusions: HoLEP videos on YouTube are not adequate to obtain proper information about the surgery. Videos uploaded by academic centres and in recent years provide more valid information for patients and urologists. To increase the value of information, online materials need to be checked, for patients to access accurate, reliable, and appropriate healthcare information.
\end{abstract}

Key words: holmium laser enucleation of prostate, benign prostatic hyperplasia, benign prostatic hyperplasia, laser prostatectomy.

\section{Introduction}

Benign prostatic hyperplasia (BPH) is a leading morbidity that causes deterioration of quality of life and is a serious economic burden, especially in men over 70 years old $[1,2]$. Transurethral resection of the prostate (TUR-P), which is still the standard sur- gical procedure in men with bothersome symptoms and prostate size lower than $80 \mathrm{ml}$, is used to relieve bladder outlet obstruction (BOO) caused by irregular proliferation of the prostate glands [3, 4]. Use of either transvesical or transcapsular open prostate adenomectomy is one of the most invasive but effective surgical techniques for prostate size greater

\section{Address for correspondence}

Emrullah Sogutdelen, Department of Urology, Bolu Abant Izzet Baysal University, Bolu Abant Izzet Baysal Training and Resarch Hospital, 14280, Golkoy, Bolu, Turkey, phone: +90 506 3388456, e-mail: esdelen@gmail.com 
than $80 \mathrm{ml}$, and it is used currently in many centres all around the world [5]. Newer technologies such as Holmium: Yttrium Aluminium Garnet (Holmium) laser enucleation of the prostate (HoLEP) has been widely used since 1995 when Gilling et al. enucleated a whole prostate adenoma even at $200 \mathrm{ml}$ and larger with shorter hospitalization time and comparable results to open prostatectomy as well as TUR-P [5-7].

Although the invention of the Internet dates back to the 1960s, its use in today's sense began in the 1980s [8]. Many platforms, like social media, which is a great area to interact with people, have been growing in popularity exponentially since 2004 . More than three and half billion social media users, expected to increase four and half billion users in 2025, are spending an average of $3 \mathrm{~h}$ to interact with each other and gather, among other things, healthcare information [9]. YouTube (Google, LLC), one of the most used social media, is a well-known video-sharing site that has over two billion users every day and contains over one billion hours of videos [10]. YouTube allows unregistered users to easily access high volumes of video content, but the quality, accuracy, and reliability of informational videos is a big problem because they are not controlled by competent people.

\section{Aim}

The trend to assess YouTube videos in urology is increasing dramatically, but the quality of the videos of some urological subjects is thought to be untrustworthy in terms of gathering appropriate information $[11,12]$. In the present study, we aimed to assess the quality of the most viewed HoLEP videos on YouTube using validated questionnaires and scoring

Table I. Global Quality Score (GQS) a

\begin{tabular}{|c|c|}
\hline (1) & $\begin{array}{l}\text { Poor quality; highly unlikely to be of any use to } \\
\text { patients }\end{array}$ \\
\hline$(2)$ & $\begin{array}{l}\text { Poor quality yet some information present; of very } \\
\text { limited use to patients }\end{array}$ \\
\hline (3) & $\begin{array}{l}\text { Suboptimal flow, some information covered but } \\
\text { important topics are missing; somewhat useful to } \\
\text { patients }\end{array}$ \\
\hline (4) & $\begin{array}{l}\text { Good quality and flow, most important topics cov- } \\
\text { ered; useful to patients }\end{array}$ \\
\hline (5) & Excellent quality and flow; highly useful to patients \\
\hline
\end{tabular}

systems developed to evaluate the significant features.

\section{Material and methods}

We conducted a YouTube search by using the keyword "Holep" on 16 June 2020, and the top 100 most viewed videos were ranked. Nonrelevant or duplicated videos were excluded from the study, and as a result 98 videos were reviewed. After saving the search results in a playlist, 3 independent HoLEP trained urologists viewed, analysed, and scored the videos individually. Discrepancies between the researchers were discussed and clarified. For scoring, the five-point Global Quality Score (GQS), which validates whether the publication is useful or not (Table I) [13], and the four-point Journal of American Medical Association Benchmark Score (JAMAS), which validates the effectiveness and accuracy of publication (Table II) [14], were used to assess the videos. The HoLEP Scoring System (HSSS), which comprises 13 questions and 1 point of each, was created by the researchers based on the European Association of Urology guidelines according to preoperative, intraoperative, and postoperative features of the HoLEP that should be present in video content (Table III).

The videos were classified according to the source of upload (academic centre, urologist, commercial, and other/unknown), video content (general information and surgical technique), type (live surgery, animation, and interview), country of origin (America, Europa, Asia, and Australia), and video language (English, other, and no audio). For each video,

Table II. Journal of American Medical Association Benchmark Criteria Scoring (JAMAS) ${ }^{b}$

(1) Authorship: The authors and contributors, the insti tutions to which they adhere, and their credentials should be provided

(2) Association: the references for all contents should have been recorded and all applicable copyright data should be noted

(3) Disclosure: the website information should be clearly and completely disclosed; for example, such information as 'ownership', sponsorship, advertising, engagement, commercial fund arrangements or support or potential conflicts of interest, etc.

(4) Validity: the dates when the content was published and updated should be indicated

${ }^{b}$ One point for each parameter. JAMAS adapted from reference [14] 
Table III. HoLEP Scoring System Score (HSSS) ${ }^{c}$

\begin{tabular}{|c|c|}
\hline \multicolumn{2}{|c|}{ Pre-operative evaluation } \\
\hline 1 & Was the age of the patient specified in the video? \\
\hline 2 & Were the patient's comorbid diseases stated in the video? \\
\hline 3 & Were the patient's medications (anticoagulant) stated in the video? \\
\hline 4 & Were the previous prostate surgeries specified in the video? \\
\hline 5 & Were preoperative abdominal imaging findings and/or prostate volume specified in the video? \\
\hline 6 & Was the uroflowmetric measurement and/or glob vesicale status specified in the video? \\
\hline \multicolumn{2}{|c|}{ During surgery } \\
\hline 1 & Were the instruments and sizes used specified in the video? \\
\hline 2 & Were the settings (power, frequency) of the laser specified in the video? \\
\hline 3 & Was the type of resection technique (bilobar, trilobar, en-bloc) utilized stated in the video \\
\hline 4 & Was the type and/or technique of morcellation given in the video? \\
\hline \multicolumn{2}{|c|}{ After surgery } \\
\hline 1 & Was the hospitalization period or discharge time specified in the video? \\
\hline 2 & Was post-operative course and possible post-operative complications (i.e. incontinence) specified in the video? \\
\hline 3 & Was any radiological and uroflowmetric examination performed to assess the efficacy of operation specified in the video? \\
\hline
\end{tabular}

the number of views, likes, dislikes, upload date, video length (second), and duration on YouTube (days) were collected.

\section{Statistical analysis}

All statistical analyses were performed using SPSS 22.0 (IBM Corp., Chicago, USA) software. The Mann-Whitney U-test and Kruskal-Wallis test were used in the analysis. Descriptive statistics were presented as mean \pm standard deviation and median (minimum-maximum) to define the parameters. Spearman correlation test was used to evaluate the correlation between variables. $P<0.05$ was considered statistically significant.

\section{Results}

After the exclusion of 2 videos, 98 videos were evaluated. Mostly urologists (63.3\%) followed by academic centres (21.4\%) provided HoLEP videos on YouTube. Surgical technique (76.5\%) and general information about surgery (17.3\%) constituted most videos. Most of the videos (51.0\%) were not audible, $91.6 \%$ of the audio videos were in English, and $80.6 \%$ of all videos were without subtitles. Four out of every 5 videos consisted of live surgery followed by an animation (8.6\%). The videos were sourced from Europe (48.9\%), Asia (25.5\%), America (19.1\%), and Austra- lia $(6.1 \%)$, respectively. The median (min.-max.) of JAMAS, GQS, and HSSS were 1 (0-3), 2 (0-4), and $1.5(0-11)$, respectively. The sources, contents, and types of video are shown in Table IV, and scores and video features are shown in Table $\mathrm{V}$.

The mean GQS and JAMAS of videos uploaded by academic centres was statistically significantly higher than videos uploaded by commercials and urologists $(2.38 \pm 0.97$ vs. $1.67 \pm 0.88 ; 1.66 \pm 0.79$ vs. $0.86 \pm 0.83$, respectively) ( $p=0.01 ; p=0.01$, respectively). The mean HSSS was significantly lower while JAMAS was significantly higher in the videos uploaded in the last 5 years compared to the period between 2009 and 2015 (2.9 \pm 2.69 vs. $1.85 \pm 2.14$; $1.0 \pm 0.55$ vs. $1.37 \pm 0.74$, respectively) $(p=0.03$; $p=0.005$, respectively). There were no differences in JAMAS, HSSS, and GQS between uploaded countries. The mean GQS and HSSS values of videos with higher likes were found to be statistically significantly higher ( $2.14 \pm 0.90$ vs. $1.62 \pm 1.06 ; 2.86 \pm 2.78$ vs. 1.75 \pm 1.91 , respectively) ( $p=0.01 ; p=0.02$, respectively). Videos including surgical technique had higher HSSS but lower GQS value than videos having other content $(2.72 \pm 2.45$ vs. $0.63 \pm 1.46 ; 1.66 \pm 0.82$ vs. $2.60 \pm 1.23)(p<0.001 ; p=0.002$, respectively). Videos with audio, either English or not, had higher GQS values than those without any audio $(2.39 \pm 1.02 \mathrm{vs}$. $1.40 \pm 0.72)(p<0.001)$. A positive correlation was 
Table IV. Sources, contents, and types of videos

\begin{tabular}{|lcc|}
\hline Parameter & Frequency, $n$ & Percentage, $\%$ \\
\hline Video sources $(n=98):$ & & \\
\hline Urologist & 62 & 63.3 \\
\hline Academic centre & 21 & 21.4 \\
\hline Private hospital & 5 & 5.1 \\
\hline Patient & 1 & 1 \\
\hline Commercial & 6 & 6.1 \\
\hline Others & 3 & 3.1 \\
\hline Video contents $(n=98):$ & & 76.5 \\
\hline Surgical technique & 75 & 17.3 \\
\hline $\begin{array}{l}\text { General information } \\
\text { about surgery }\end{array}$ & 17 & 5.1 \\
\hline Advertisement & 5 & 1 \\
\hline Patient experience & 1 & 84.9 \\
\hline Video types $(n=93):$ & & 8.6 \\
\hline Live surgery & 79 & 5.4 \\
\hline Animation & 8 & 1 \\
\hline Interview & 5 & 1 \\
\hline Picture & & \\
\hline
\end{tabular}

Table VI. Comparison of scores according to video features

\begin{tabular}{|c|c|c|c|c|c|c|}
\hline Variable & JAMAS & $P$-value & GQS & $P$-value & HSSS & $P$-value \\
\hline \multicolumn{7}{|l|}{ Upload years: } \\
\hline $\begin{array}{l}2009-2015(n=40) \text { median (min.-max.) } \\
\text { Mean } \pm \text { SD }\end{array}$ & $\begin{array}{l}1(0-3) \\
1 \pm 0.55\end{array}$ & \multirow[t]{2}{*}{0.005} & $\begin{array}{c}2(0-4) \\
1.82 \pm 0.93\end{array}$ & \multirow[t]{2}{*}{0.61} & $\begin{array}{c}2(0-11) \\
2.9 \pm 2.69\end{array}$ & \multirow[t]{2}{*}{0.03} \\
\hline $\begin{array}{l}2016-2020(n=58) \text { median (min.-max.) } \\
\text { Mean } \pm \text { SD }\end{array}$ & $\begin{array}{c}1(0-3) \\
1.37 \pm 0.74\end{array}$ & & $\begin{array}{c}2(1-4) \\
1.93 \pm 1.07\end{array}$ & & $\begin{array}{c}1(0-9) \\
1.85 \pm 2.14\end{array}$ & \\
\hline \multicolumn{7}{|l|}{ Audio: } \\
\hline $\begin{array}{l}\text { Yes }(n=48) \text { median (min.-max.) } \\
\text { Mean } \pm \text { SD }\end{array}$ & $\begin{array}{c}1(0-3) \\
1.25 \pm 0.60\end{array}$ & \multirow[t]{2}{*}{0.72} & $\begin{array}{c}1(0-4) \\
2.39 \pm 1.02\end{array}$ & \multirow[t]{2}{*}{$<0.001$} & $\begin{array}{c}1(0-11) \\
2.11 \pm 2.78\end{array}$ & \multirow[t]{2}{*}{0.49} \\
\hline $\begin{array}{l}\text { No }(n=50) \text { median (min.-max.) } \\
\text { Mean } \pm \text { SD }\end{array}$ & $\begin{array}{c}1(0-3) \\
1.20 \pm 0.78\end{array}$ & & $\begin{array}{c}1(0-4) \\
1.4 \pm 0.72\end{array}$ & & $\begin{array}{c}2(0-8) \\
2.46 \pm 2.09\end{array}$ & \\
\hline \multicolumn{7}{|l|}{ Video sources: } \\
\hline Urologist $(n=62)$ mean \pm SD & $1.16 \pm 0.54$ & \multirow[t]{3}{*}{0.01} & $1.67 \pm 0.88$ & \multirow[t]{3}{*}{0.01} & $2.38 \pm 2.53$ & \multirow[t]{3}{*}{0.82} \\
\hline Academic centre $(n=21)$ mean \pm SD & $1.66 \pm 079$ & & $2.38 \pm 0.97$ & & $2.30 \pm 2.00$ & \\
\hline Commercial and patient $(n=15)$ mean \pm SD & $0.86 \pm 0.83$ & & $2.06 \pm 1.33$ & & $1.92 \pm 2.67$ & \\
\hline \multicolumn{7}{|l|}{ Video contents: } \\
\hline Surgical technique $(n=75)$ mean \pm SD & $1.24 \pm 0.67$ & \multirow[t]{3}{*}{0.92} & $1.66 \pm 0.82$ & \multirow[t]{3}{*}{$<0.001$} & $2.72 \pm 2.45$ & \multirow[t]{3}{*}{0.002} \\
\hline General information $(n=17)$ mean \pm SD & $1.17 \pm 0.88$ & & $2.52 \pm 1.28$ & & $0.5 \pm 1.40$ & \\
\hline $\begin{array}{l}\text { Advertisement and patient experience } \\
(n=6) \text { mean } \pm \text { SD }\end{array}$ & $1.16 \pm 0.40$ & & $2.83 \pm 1.16$ & & $1.0 \pm 1.73$ & \\
\hline
\end{tabular}

Data are presented as median (min-max) and mean \pm SD. $n$ - number, min. - minimum, max. - maximum, SD - standard deviation, JAMAS - Journal of American Medical Association Benchmark Score, GQS - Global Quality Score, HSSS - HoLEP Scoring System Score. One-way ANOVA and Tukey's post hoc tests were used to assess statistically significant differences, seen in bold, between groups.

\begin{tabular}{|lcc|}
\hline Variable & Mean \pm SD & Median (min.-max.) \\
\hline Video Scores $(n=98):$ & & \\
\hline JAMAS & $1.22 \pm 0.69$ & $1(0-3)$ \\
\hline GQS & $1.88 \pm 1.01$ & $2(0-4)$ \\
\hline HSSS & $2.29 \pm 2.43$ & $2(1-6)$ \\
\hline Video Features $(n=98):$ & & \\
\hline Video length $(s)$ & $986.7 \pm 957.7$ & $501(20-4579)$ \\
\hline View $(n)$ & $6346 \pm 10286$ & $3026(378-57177)$ \\
\hline Like $(n)$ & $28.73 \pm 81.81$ & $8(0-684)$ \\
\hline Dislike $(n)$ & $1.98 \pm 4.63$ & $0(0-29)$ \\
\hline Duration [days] & $1588.4 \pm 1068.1$ & $1299.5(85-3984)$ \\
\hline
\end{tabular}

Data are presented as mean $\pm S D$ and median (min.-max.). $n$ - number, $s$ - seconds, $d$-days, min. - minimum, max. - maximum, SD - standard deviation, JAMAS - Journal of American Medical Association Benchmark Score, GQS - Global Quality Score, HSSS - HoLEP Scoring System Score.

found in between HSSS and GQS, HSSS and JAMAS, and GQS and view numbers $(r=0.238, p=0.21 ; r=$ $0.206, p=0.04 ; r=0.255, p=0.01$, respectively). All the comparisons of scores according to video features are shown in Table VI.

ed to assess statistically significant differences, seen in bold, between groups. 


\section{Discussion}

The Internet has become one of the most commonly used places to gather healthcare information. Social media platforms such as YouTube also make it possible to obtain health information and to understand it more easily with the help of videos. As much as $90 \%$ of health care providers use social media, with an average of $1 \mathrm{~h}$ a day, and $85 \%$ of health care practitioners agree that social media is a practical and effective tool for educational purposes [15]. YouTube videos were evaluated in various medical sectors including urology, rheumatology, orthopaedic, and neurosurgery in terms of video quality [16]. Information on video quality about prostate cancer and BPH surgeries was previously evaluated [11, 12]. However, HoLEP videos, specifically, on YouTube have not been considered by 3 different scores. In the present study, we aimed to evaluate the quality, informativity, and reliability of HoLEP videos on YouTube.

In our study, videos were commonly about surgical technique and were uploaded by urologists with median JAMAS, GQS, and HSSS values of 1,2 , and 1.5 , respectively. All these scores were found to be too low to obtain adequate and accurate information about HoLEP because the uploaded videos did not attain certain standards, were not checked by expert persons in their fields, and were not controlled by local or global healthcare authorities.

The higher GQS was found especially composed of highly liked videos and videos with audio. It seems that people prefer videos with audio and hit the like button if that video has adequate quality to obtain appropriate HoLEP information. Videos provided by academic centres and uploaded in the last 5 years, compared to older ones, were found to have higher JAMAS scores, indicating higher validity; it was expected that newer videos and an expert's view in an academic centre would influence the score because urologists, especially in academic centres, know the questions that need to be answered and they know well what needs to be paid attention in the video.

HSSS is a score that was created to standardize videos in which preoperative, operative, and postoperative information should be mentioned about HoLEP in the video. Therefore, higher HSSS scores were seen in the videos where the surgical technique was included. Surprisingly, despite the increased volume of research about the quality of publications or video content recently, the HSSS of videos uploaded in the last 5 years was found to be lower.

Our study has some limitations. Our sample includes a search of only one keyword and was of quite a small size, i.e. just the 100 most viewed videos instead of all uploaded content, but we think that our sample is sufficient to interpret and to makes inferences given the similar strategies on search $[14,17]$. Although interpretation of videos is person-dependent, 3 independent urologists scored the videos to minimize the impact of person-based interpretation of the videos. Besides these limitations, we believe that these results will affect people who want to give medical information via videos and make a significant contribution to the current literature because this is the first study using quality and validity scores specifically for HoLEP videos on YouTube.

\section{Conclusions}

HoLEP videos on YouTube are not adequate to obtain proper surgical and technical information. Videos uploaded by academic centres and in recent years provide more valid information for patients. Healthcare professionals and society should work collectively to increase the truthfulness of videos containing healthcare information because it negatively affects patient-physician communication [18]. Information obtained from social media is having a greater impact on patients. Therefore, it is becoming more difficult to correct the effects of misinformation. Therefore, videos need to be more standardized, so that the viewers can access accurate, reliable, and relevant information.

\section{Conflict of interest}

The authors declare no conflict of interest.

\section{References}

1. Wei JT, Calhoun E, Jacobsen SJ. Urologic diseases in America project: benign prostatic hyperplasia. J Urol 2005; 173: 1256-61.

2. Kupelian V, Wei JT, O'Leary MP, et al.Prevalence of lower urinary tract symptoms and effect on quality of life in a racially and ethnically diverse random sample: The Boston Area Community Health (BACH) survey. Arch Intern Med 2006; 166: 2381-7.

3. Chua ME, Mendoza J, See $M$, et al. A critical review of recent clinical practice guidelines on the diagnosis and treatment of non-neurogenic male lower urinary tract symptoms. Can Urol Assoc J 2015; 9: E463-70.

4. Gratzke C, Bachmann A, Descazeaud A, et al. EAU guidelines on the assessment of non-neurogenic male lower urinary tract 
symptoms including benign prostatic obstruction. Eur Urol 2015; 67: 1099-109.

5. Gratzke C, Schlenker B, Seitz M, et al. Complications and early postoperative outcome after open prostatectomy in patients with benign prostatic enlargement: results of a prospective multicenter study. J Urol 2007; 177: 1419-22.

6. Zell MA, Abdul-Muhsin H, Navaratnam A, et al. Holmium laser enucleation of the prostate for very large benign prostatic hyperplasia ( $\geq 200$ cc). World J Urol 2021; 39: 129-34.

7. Gilling PJ, Cass CB, Cresswell MD, Fraundorfer MR. Holmium laser resection of the prostate: Preliminary results of a new method for the treatment of benign prostatic hyperplasia. Urology 1996; 47: 48-51.

8. Who Invented the Internet? Britannica, (n.d.). https://www. britannica.com/story/who-invented-the-internet (accessed September 15, 2020).

9. 10 Social Media Statistics You Need to Know in 2020 [Infographic], (n.d.). https://www.oberlo.com/blog/social-mediamarketing-statistics (accessed September 1, 2020).

10. YouTube statistics page, Basın - YouTube, (n.d.). https://www. youtube.com/about/press/ (accessed September 1, 2020).

11. Betschart P, Pratsinis M, Müllhaupt G, et al. Information on surgical treatment of benign prostatic hyperplasia on YouTube is highly biased and misleading. BJU Int 2020; 125: 595-601.

12. Carneiro B, Dizon DS. Prostate cancer social media: in youtube we trust? Eur Urol 2019; 75: 568-9.

13. Bernard A, Langille M, Hughes S, et al. A systematic review of patient inflammatory bowel disease information resources on the world wide web. Am J Gastroenterol 2007; 102: 2070-7.

14. Silberg WM, Lundberg GD, Musacchio RA. Assessing, controlling, and assuring the quality of medical information on the Internet. Caveant lector et viewor - let the reader and viewer beware, generations. JAMA 1997; 277: 1244-5.

15. Pizzuti AG, Patel KH, McCreary EK, et al. Healthcare practitioners' views of social media as an educational resource. PLoS One 2020; 15: https://doi.org/10.1371/journal.pone.0228372.

16. Madathil KC, Rivera-Rodriguez AJ, Greenstein JS, Gramopadhye AK. Healthcare information on YouTube: a systematic review. Health Informatics J 2015; 21: 173-94.

17. Morahan-Martin JM. How internet users find, evaluate, and use online health information: a cross-cultural review. Cyberpsychology Behav 2004; 7: 497-510.

18. Langford A, Loeb S. Perceived patient-provider communication quality and sociodemographic factors associated with watching health-related videos on YouTube: a cross-sectional analysis. J Med Internet Res 2019; 21. https://doi.org/10.2196/13512.

Received: 1.04.2021, accepted: 10.05.2021 